\title{
PROCEDIMENTO PARA INSPEÇÃO E DIAGNÓSTICO DE PATOLOGIAS PROVENIENTES DE INFILTRAÇÃO E UMIDADE EM EDIFICAÇÕES: ESTUDO DE CASO NO INSTITUTO FEDERAL DE GOIÁS - CÂMPUS GOIÂNIA
}

\author{
MARTINS, WILIAM SILVA \\ Graduando em Engenharia Civil \\ Instituto Federal de Goiás - Câmpus Goiânia \\ Goiás; Brasil \\ willsilvamart@gmail.com
}

\author{
MENDES, MARCUS VINÍCIUS A. SILVA \\ Docente/Engenheiro Civil \\ Instituto Federal de Goiás - Câmpus Goiânia \\ Goiás; Brasil \\ marcus.mendes@ifg.edu.br
}

\author{
PITALUGA, DOUGLAS PEREIRA DA SILVA \\ Docente/Tecnólogo em Construção Civil \\ Instituto Federal de Goiás - Câmpus Goiânia \\ Goiás; Brasil \\ douglas.pitaluga@ifg.edu.br
}

\section{RESUMO}

Tendo em vista às patologias nas edificações, aquelas oriundas de infiltração e umidade são as mais habituais na construção civil. Ao transportar agentes agressivos a umidade promove o surgimento de patologias na edificação, que podem comprometer a sua funcionalidade, refletindo em desconforto aos usuários e prejuízos financeiros. Sendo assim, as manutenções preventivas nas edificações, bem como a maneira de geri-las se torna imprescindível. Diante do exposto, desenvolveu-se um estudo sobre patologias das construções no Instituto Federal de Goiás - Câmpus Goiânia (IFG Câmpus Goiânia), que possui edifícios tombados pelo Instituto do Patrimônio Histórico e Artístico Nacional (IPHAN). Foram empregados dois métodos de inspeção predial: o Boletim Técnico 06/86 publicado por Lichtenstein e a Norma de Inspeção Predial Nacional, criada pelo IBAPE/SP. Constataram-se vários pontos de descolamento e empolamento da pintura nas alvenarias da fachada, manchas de sujidade próximas às janelas e nos frisos comuns em edifícios de arquitetura art déco. Concebeu-se um procedimento prático e sucinto às inspeções prediais no IFG - Câmpus Goiânia com vistas às patologias provenientes de infiltração e umidade, em virtude de sua preponderancia. Neste procedimento prático, há fichas de inspeção e a cartilha de condutas que lista as prováveis causas e origens dos danos identificados tornando mais fácil a definição da conduta de intervenção mais adequada para cada caso. Por fim, os dados compilados na cartilha podem ser base para aquisição de subsídios necessários para o diagnóstico de ocorrências semelhantes, e oacompanhamento dos resultados e a comparação entre os efeitos provocados e os esperados geram a retroalimentação da cartilha.

Palavras-chave: inspeção predial, patologia, diagnóstico, cartilha de condutas.

\section{ABSTRACT}

In view of the pathologies in buildings, those from infiltration and humidity are the most usual in civil construction. When carrying aggressive agents the humidity promotes of pathologies in the building that may compromise its functionality, reflecting users discomfort and financial losses. Thus, preventive maintenance on buildings, as well as the way to manage them becomes essential. Given the above, a study on building pathologies was developed at the Federal Institute of Goias - Campus Goiania (IFG - Campus Goiania), located in the Central Sector, which has buildings listed by the Institute of National Historical and Artistic Heritage (IPHAN). Two methods of building inspection were employed: Technical Bulletin 06/86 published by Lichtenstein and the National Building Inspection Standard, created by IBAPE/SP. Several spots of detachment and blistering of the painting were found on the masonry of the façade, dirt stains near the windows and on the common friezes in buildings of art deco architecture. A practical and succinct procedure for building inspections at the IFG - Campus Goiania was conceived with a view to pathologies arising from infiltration and humidity, due to its preponderance. In this practical procedure, there are inspection sheets and the conduit booklet that lists the probable causes and origins of the damage identified making it easier to define the most appropriate intervention conduct for each case. Finally, the data compiled in the booklet can be the basis for capturing the necessary subsidies for diagnosing occurrences, and monitoring results and comparing the effects caused and expected generated by the feedback from the booklet.

Keywords: building inspection, pathology, diagnosis, conduit booklet. 


\section{INTRODUÇÃO}

Em relação às patologias na construção civil, as provenientes de infiltração e umidade são as mais comuns e tidas como as mais complexas, devido às dificuldades de correções, a diversidade de fenômenos envolvidos e a falta de pesquisas para melhorar a impermeabilização dos materiais empregados (RODRIGUES; JÚNIOR; LIMA, 2016). A umidade age como transporte de agentes agressivos promovendo o surgimento de patologias na edificação que podem comprometer a sua funcionalidade, refletindo em desconforto aos usuários e prejuízos financeiros. O conhecimento das formas de manifestações patológicas por umidade é essencial para identificar as causas, analisar as patologias, e propor as medidas mitigativas necessárias para solucionar o problema.

Segundo Cechinel et al. (2011), a umidade nas edificações pode ser manifestada por capilaridade, precipitação pluviométrica, condensação, infiltração e percolação. A ausência de manutenção ou falta da impermeabilização pode permitir que a água penetre em alvenarias e lajes, podendo prejudicar a saúde dos usuários, vida útil da estrutura e parte estética da edificação (HUSSEIN, 2013).

Faz-se necessária a preocupação com as manutenções preventivas nas edificações, bem como a maneira de geri-las. Diante dessa problemática, desenvolveu-se um estudo sobre patologias provenientes de infiltração e umidade no Instituto Federal de Educação, Ciência e Tecnologia Goiás - Câmpus Goiânia (IFG - Câmpus Goiânia), localizado no Setor Central, que possui edifícios tombados pelo Instituto do Patrimônio Histórico e Artístico Nacional (IPHAN). Investigou-se a origem das patologias e suas prováveis causas a partir da inspeção visual e busca por documentos e históricos de intervenção com a finalidade de propor medidas mitigadoras para os problemas levantados. Cabe destacar que a relevância deste trabalho se deve à necessidade de adotar um procedimento de inspeção predial eficaz que considere os efeitos das manutenções e reformas anteriores como fonte de aquisição dos subsídios necessários para o prognóstico de casos semelhantes. Abrange também, a preocupação com os gastos para os cofres públicos, uma vez que a falta de manutenção em obras públicas faz com que pequenas patologias evoluam para situações insatisfatórias de ambientes insalubres, estruturas comprometidas, alteração estética e alto custo de recuperação.

Nas edificações do IFG - Câmpus Goiânia observam-se diversos pontos prejudicados pela umidade, principalmente nos blocos 100 e 200, que foram construídos na década de 1940 e são tombados pelo IPHAN, até os que foram concebidos em ampliações posteriores. Além disso, verificam-se problemas crônicos nos edifícios tombados em determinadas regiões dos edifícios, os quais não são resolvidos definitivamente devido às regras do IPHAN que limitam às intervenções, assim prejudicando as ações adequadas de manutenção. Ou seja, a falta de eficiência das manutenções em obras públicas e tombadas faz com que pequenas patologias evoluam para situações mais degradantes, tornando a intervenção corretiva cada vez mais onerosa.

Pelo exposto, faz-se importante a elaboração de um procedimento prático para o levantamento das patologias provenientes de infiltração e umidade no IFG - Câmpus Goiânia, a fim de identificar as causas e origens, bem como na escolha da conduta mais adequada para solucionar o problema. A descrição e a comparação dos métodos de inspeção permitem extrair as informações mais importantes para a concepção de uma inspeção eficiente, com ênfase nos requisitos para o diagnóstico da situação. Cabe destacar, que os dados obtidos com este procedimento devem ser usados para o acompanhamento do funcionamento e desempenho dos diversos sistemas da edificação após a intervenção, com serviços que serão empregados em cada patologia identificada no Câmpus, tendo em vista as ações corretivas necessárias para eliminar as reais causas do problema na pretensão de manter a edificação em bom estado de conservação e desempenho, e por fim assegurando sua retroalimentação.

\section{OBJETIVOS}

O objetivo geral deste artigo é propor um procedimento prático para as inspeções prediais no Instituto Federal de Goiás - Câmpus Goiânia (IFG - Câmpus Goiânia), tendo em vista as patologias provenientes de infiltração e umidade.

Os objetivos específicos são: identificar as patologias provenientes de infiltração e umidade por meio de inspeção visual e com auxílio de documentos que constam o histórico de reformas e problemas já identificados; analisar a origem e as possíveis causas das anomalias encontradas; apontar a definição de conduta mais conveniente para cada caso estudado; criar fichas de inspeção para nortear o que deve ser observado durante a perícia; criar a cartilha de condutas para indicar e descrever as intervenções recomendadas para cada patologia encontrada. 


\section{REVISÃO BIBLIOGRÁFICA}

De acordo com a NBR 15575-1 (ABNT, 2013), define-se vida útil como o período de tempo decorrido em que um edifício mantém a capacidade funcional para a qual foi projetada e construída, se realizados corretamente e periodicamente os processos de manutenção e conservação, especificados no Manual de Uso, Operação e Manutenção, que é elaborado conforme a norma NBR 14037 (ABNT, 2014).

A definição de desempenho é colocada por Melo Júnior (2016) como sendo os requisitos que a edificação deve atender, independente dos materiais e procedimentos usados para a construção. Isto é, relacionar as funções exigidas às edificações e seus sistemas em utilização. Para estabelecer o desempenho de um material, componente, elemento ou sistema construtivo, a NBR 15575-1 (ABNT, 2013) expõe a definição de requisitos (qualitativos), critérios (quantitativos) e métodos de verificação que permitam a mensuração clara do seu cumprimento.

A NBR 15575-1 (ABNT, 2013) define durabilidade como a capacidade da edificação em manter-se em serviço, sob condições de uso e manutenção especificadas, ao longo do tempo. A durabilidade pode ser explicada em função do tempo em vida ou em relação à capacidade de resistência aos agentes de degradação: a agressividade do meio ambiente, a interação entre os elementos ao longo do tempo e as propriedades de cada um deles (MELO JÚNIOR, 2016). Como requisitos de durabilidade, devem ser realizadas as intervenções de manutenção e conservação periodicamente, sendo manutenção definida pela norma NBR 5462 (ABNT, 1994) como a combinação de todas as ações técnicas e administrativas destinadas a manter ou recolocar um item em um estado no qual possa desempenhar uma função requerida. Sua finalidade não é somente reparar algum problema, mas também agir antes que eles ocorram e é usada até mesmo como acompanhamento das condições da edificação.

A manutenção preventiva é efetuada em intervalos predeterminados e periódicos, destinada a reduzir a probabilidade de falha ou a degradação do funcionamento da edificação (ABNT NBR 5462, 1994). Segundo Dardengo (2010) a manutenção preventiva tem como objetivo prever as falhas antes de acontecerem, de forma a evitar e minimizar a necessidade de manutenção corretiva, que está diretamente ligada ao aparecimento de manifestações patológicas. A NBR 5462 (ABNT, 1994) define manutenção corretiva como a manutenção efetuada após a ocorrência da incapacidade de um item desempenhar uma função requerida. Dessa forma, os custos para correção são elevados mediante a urgência na realização dos reparos, somando também os materiais e mão de obra envolvidos e custos das perdas. A manutenção preditiva pode ser entendida como uma atividade de programação das intervenções a partir do acompanhamento sistemático do funcionamento e desempenho dos diversos sistemas da edificação (DARDENGO, 2010; SILVA, B., 2013). Trata-se de um processo que prediz o tempo de vida útil dos componentes dos subsistemas e as condições para que esse tempo de vida seja bem aproveitado. Assim, é possível determinar antecipadamente a necessidade de serviços de manutenção num elemento específico de um sistema.

Inspeção predial é, portanto, a análise isolada ou combinada dos requisitos técnicos, de uso e de manutenção da edificação (IBAPE/SP, 2012). Os métodos de inspeção predial podem ser entendidos como a estrutura ou ordenação das etapas de como proceder para diagnosticar as patologias nas edificações.

Flores-Colen (2009) indica que as técnicas de inspeção podem compreender métodos experimentais, que constituem a utilização de equipamentos nos diversos tipos de ensaios, podendo ser em laboratório ou no local de estudo e métodos empíricos, que são fundamentados na inspeção visual com o auxílio de dados históricos da edificação, como o acesso a projetos executivos e as built, especificações de materiais, registros fotográficos, manutenções e intervenções anteriores.

Lichtenstein (1986) apresenta que há uma quantidade enorme de edifícios com problemas relacionados ao desempenho insatisfatório e que, grande parte desses problemas, pode ser resolvido desde que receba uma análise metódica e individualizada. Até então não existia um método e um procedimento prático para o diagnóstico de patologias, partindo apenas da experiência prática do profissional, que por ser meramente intuitiva, facilmente sucedia-se em enganos. Quanto à ciência, ele diz que esta requer um pensamento conceitual passível de comunicação e uma abordagem não apenas intuitiva. Norberto Blumenfeld Lichtenstein publicou o Boletim Técnico 06/86 intitulado "Patologia das construções: procedimento para diagnóstico e recuperação", que apresenta um procedimento genérico que pode ser empregado independente da experiência do técnico e da complexidade do problema, o fluxograma, Figura 1, mostra as etapas para o diagnóstico e recuperação de patologias na construção proposto por Lichtenstein (1986). 


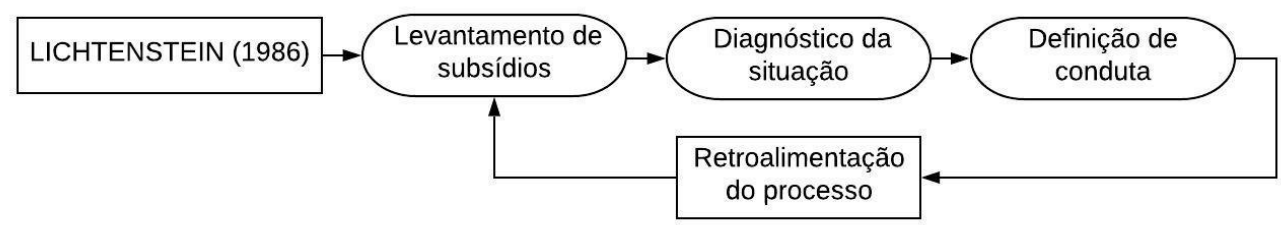

Figura 1: Fluxograma do procedimento proposto por Lichetenstein (1986)

O Instituto Brasileiro de Avaliações e Perícias de Engenharia (IBAPE) é o órgão federativo da classe formado por profissionais de Engenharia, Arquitetura e Agronomia, sem fins lucrativos, com o objetivo de reunir os institutos estaduais para a divulgação de informações técnicas com a elaboração de normas e estudos. Desse modo, disponibilizou-se em 2012 a Norma de Inspeção Predial Nacional, baseada em texto normativo da filial do estado de São Paulo para atender à ABNT NBR 5674:2012, ABNT NBR 15575-1:2013 e também para colaborar com a segurança dos edifícios, funcionalidade, manutenção adequada e valorização patrimonial.

A Norma de Inspeção Predial Nacional classifica as não conformidades constatadas nas edificações quanto à origem e grau de risco, indicando orientações técnicas necessárias para a realização da inspeção e propor a melhoria da manutenção dos sistemas construtivos. No entanto, estes aspectos não são associados diretamente às eventuais patologias que são encontradas em edifícios, tornando-se subjetivo ao profissional responsável pela inspeção avaliar o grau de risco, sendo de responsabilidade e exclusiva competência dos engenheiros e arquitetos, legalmente habilitados pelos Conselhos Regionais de Engenharia e Agronomia - CREAs e Conselhos de Arquitetura e Urbanismo - CAUs. Quanto à inspeção predial, esta norma classifica a sua natureza, institui as terminologias a serem utilizadas, define a metodologia básica aplicável, estabelece os critérios a serem empregados nos trabalhos e prescreve a diretriz para apresentação de laudos e pareceres técnicos. O fluxograma, Figura 2, mostra as etapas para a elaboração da inspeção predial pelo método proposto pelo IBAPE/SP (2012).

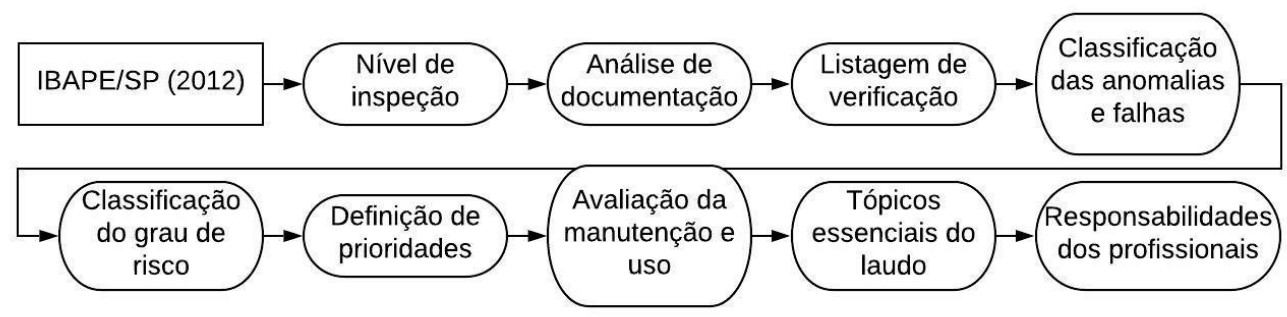

Figura 2: Fluxograma do método de inspeção IBAPE/SP (2012)

As patologias no ramo da construção civil podem ser entendidas como uma não conformidade que se manifesta no produto em função de falhas no projeto, na industrialização, na execução ou montagem, no uso ou na manutenção bem como problemas que não decorram do envelhecimento natural do elemento (ABNT NBR 15575-1, 2013). Dentre as manifestações patológicas, segundo Souza (2008), as provenientes da formação de manchas de umidade são as mais comuns na construção civil. Verçoza (1991) e Souza (2008), expõem que a umidade não é apenas uma causa de patologias, mas também age como intermédio para o aparecimento de outras que podem até causar acidentes estruturais. Tais defeitos geram graves problemas de difíceis soluções, provocando prejuízos de caráter funcional da edificação, desconforto dos usuários, danos em equipamentos presentes no interior das edificações e diversos prejuízos financeiros.

Castro e Martins (2014) evidenciam que a umidade pode ser originária da absorção de água do solo por capilaridade e migração por percolação; infiltração resultante das águas das chuvas; condensação provocada pela umidade do ar e vapor d'água; acidental, provocada por vazamentos em instalações hidrossanitárias. A presença de infiltração e umidade nas edificações ocasionam diversos danos que decorrem em patologias que prejudicam a durabilidade e desempenho dos elementos envolvidos, tais como bolor ou mofo, carbonatação do concreto, corrosão da armadura, lixiviação e eflorescência, sujidade, descolamento, empolamento e vesículas.

Para a análise de problemas patológicos, cabe identificar não tão somente a causa, mas também a origem, isto é, em qual etapa do processo construtivo foram criadas as condições para as anomalias se manifestarem e desenvolvessem (ISAIA, 2010; CASTRO; MARTINS, 2014). As patologias podem se manifestar nas etapas de construção do edifício quando não 
há um planejamento eficiente, abrangendo a ausência de projetos, erros nas especificações dos materiais, execução com mão de obra deficitária ou durante o uso e operação após a entrega da obra.

Em linhas gerais, o art déco foi um conjunto de manifestações artísticas que objetivava exteriorizar um espírito moderno através da arte decorativa (MUNDURUCA, 2013). Alguns detalhes construtivos nas fachadas com art déco podem contribuir para o acúmulo de água e, consequentemente, no surgimento de patologias: ausência de pingadeiras que interceptam a lâmina da água no plano das platibandas, causando a retenção de umidade e o surgimento de manchas escuras com o desenvolvimento de micro-organismos e sujidade nas fachadas (ANTUNES, 2010).

\section{METODOLOGIA}

Neste trabalho foram abordados e discutidos dois métodos de inspeção predial: o Boletim Técnico 06/86 publicado por Lichtenstein em 1986 e intitulado "Patologia das construções: procedimento para diagnóstico e recuperação" e a Norma de Inspeção Predial Nacional, criada pelo IBAPE/SP em 2012.

Para o emprego dos métodos, foi realizado o levantamento das patologias provenientes de infiltração e umidade, no Instituto Federal de Goiás - Câmpus Goiânia, especialmente nas fachadas dos pavilhões e em áreas molhadas, sendo abordado o bloco 100, tombado pelo IPHAN. A escolha do local para estudo permeia da necessidade de intervenções nos blocos do Câmpus, devido à grande quantidade de patologias percebidas, desde os blocos tombados pelo IPHAN até os que foram concebidos em reformas posteriores.

O objeto do estudo de caso, IFG - Câmpus Goiânia, está localizado entre as Ruas 66, 79, 69 e Rua 75, no Setor Central, conforme Figura 3. O projeto arquitetônico em arquivo digital para apresentação da área de estudo foi fornecido pela Gerência de Apoio Administrativo e Manutenção (GAAM) do IFG - Câmpus Goiânia.

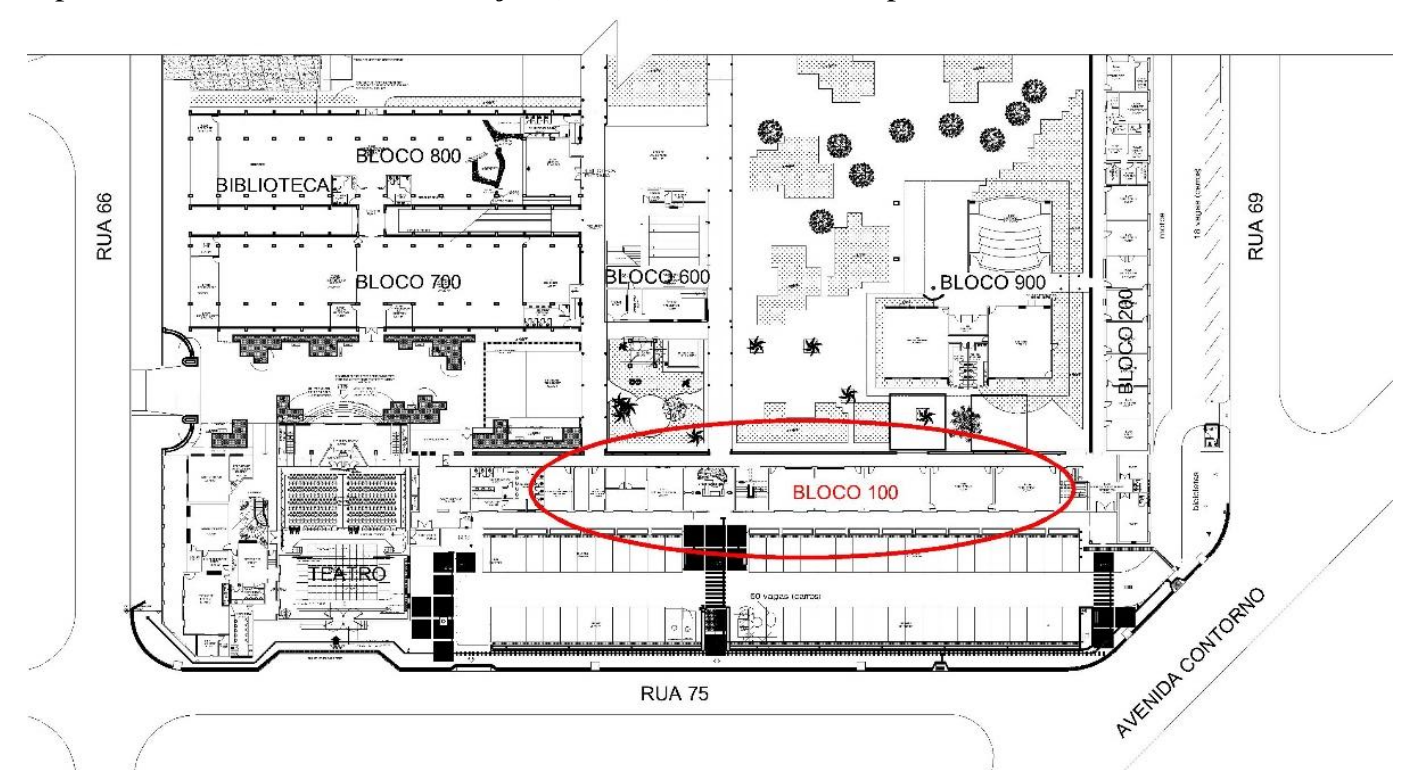

Figura 3: Planta baixa do IFG - Campus Goiânia com blocos nomeados e área de estudo indicada

Apoiados no estudo de caso, os métodos foram comparados e confrontados com o desfecho do levantamento realizado, sendo possível distinguir a abrangência e o rigor de cada técnica. Por fim, foi proposto um procedimento próprio para as inspeções na Instituição, customizando de forma sucinta uma metodologia que aborde a sucessão das etapas desde a identificação da patologia à solução do problema, com base nas comparações realizadas e sintetizando as informações mais importantes.

$\mathrm{Na}$ área de estudo, a inspeção visual foi realizada com o objetivo principal de identificar os danos causados pela umidade para o levantamento das patologias existentes, a fim de relacionar estas ocorrências ao que originou o problema, com o intuito de apontar a conduta necessária para dirimir sua causa. Para patologias com o grau de complexidade e risco maior, que podem provocar danos contra a saúde e segurança dos usuários ou perda excessiva de desempenho e funcionalidade, faz-se necessário a adoção de exames complementares, que apresentem as informações não obtidas pelos sentidos 
naturais, através de meios físicos, químicos ou biológicos, podendo ser classificados em análises laboratoriais e ensaios in loco, conforme proposto por Lichtenstein (1986).

As visitas para as inspeções foram realizadas no período matutino, em períodos chuvosos e em períodos de estiagem, com a intenção de comparar a possível evolução das patologias com a incidência das chuvas. Durante as inspeções ao longo do trabalho, realizaram-se registros fotográficos das manifestações visualizadas e, observou-se que há a ocorrência de várias patologias em comum em todo o Câmpus e, por isso, serão dissertadas aquelas presentes na área delimitada como objeto de estudo uma vez que são representativas para a maior parte das patologias existentes na Instituição, condizente com o esperado.

A Gerência de Apoio Administrativo e Manutenção do IFG - Câmpus Goiânia disponibilizou os registros existentes e, com isso, tentou-se inteirar-se das possíveis causas das patologias levantadas. Neste contexto, o histórico das ações já praticadas na resolução de uma patologia faz-se necessária e de suma importância para o conhecimento e entendimento da evolução ou solução do problema.

O diagnóstico pode ser entendido como a explicação científica dos fenômenos ocorridos e seu desenvolvimento. As causas principais são responsáveis pelo aparecimento do problema e provocam alterações nos materiais, geralmente associadas à ação de agentes físicos e biológicos e, as causas coadjuvantes, estão relacionadas com a idade do edifício e a falta de conservação e manutenção. A seguir define-se a conduta para intervenção. Na fase de avaliação e escolha da conduta, as ações são hierarquizadas de acordo com suas possíveis consequências. A escolha racional representa aquela baseada no melhor custo-benefício, que busca o melhor desempenho possível dentro do menor custo conseguível. Depois de estimada a relação custo-benefício e o grau de incerteza, listam-se as técnicas de execução e materiais e equipamentos envolvidos na realização das atividades propostas em cada conduta.

As fichas de inspeção consistem na representação sinóptica das informações referentes às manifestações de deteriorações da edificação, discriminadas de forma rigorosa, mas sucinta, sintetizando o resultado das investigações numa determinada data e tempo. Trata-se de um dos primeiros documentos técnicos para a definição da intervenção na edificação. A elaboração das fichas de inspeção se deu a partir da especificidade e abrangência percebida em ambos os métodos de inspeção estudados. Pretende-se apresentar as fichas sob a forma de formulário (impressas ou em meio digital), com tamanho e formatação apropriados para possibilitar um fácil manuseio e rápida compreensão. As fichas devem conter anotações e registros fotográficos (quando em meio digital) sobre os danos nos elementos de uma edificação. A partir das fichas de inspeção, espera-se que seja possível identificar a origem e a causa da patologia referida, tornando possível dirimir as incertezas inerentes ao diagnóstico e aperfeiçoando cada vez mais as decisões a serem tomadas.

O processo de resolução de uma patologia pode ser entendido como o círculo de "informação-decisão-ação-informaçãodecisão", assim sendo, a divulgação da história do problema patológico e de sua solução configura que o conhecimento técnico e científico empregados e adquiridos durante o processo sejam formalizados. Este registro torna-se fonte para a aquisição de subsídios necessários para o diagnóstico de casos semelhantes e a definição da conduta mais apropriada (LICHTENSTEIN, 1986). Desta maneira, almeja-se a elaboração de uma cartilha de condutas que reúna as intervenções mais eficientes e apropriadas para cada patologia levantada, classificando-as quanto à origem, causa ou danos/efeitos. Ou seja, com o resultado dos estudos e análises feitas sobre a patologia, propor algumas condutas como alternativas para a solução do problema.

\section{RESULTADOS E DISCUSSÃO}

\subsection{Inspeção predial da área estudada}

A escolha do bloco 100, construído na década de 1940 no estilo art déco, foi pensada para abordar parte do IFG - Câmpus Goiânia que é tombado pelo IPHAN. O tombamento de um bem pró́be a destruição e descaracterização e é aplicado a bens de interesse para a preservação da memória e referenciais coletivos (CAETANO, 2018). Por isso, as manutenções e reparos neste pavilhão são realizados mediante solicitação da GAAM (IFG - Câmpus Goiânia) e somente após resposta do IPHAN com as delimitações e especificações dos serviços e materiais permitidos que se realizam as intervenções.

Pelo método Lichtenstein (1986) realizou-se o levantamento das patologias provenientes de infiltrações e umidade. Iniciou-se com a inspeção visual da fachada voltada à Rua 75. Notaram-se alguns pontos de descolamento e empolamento da pintura nas alvenarias da fachada, Figura 4a, laje de cobertura do acesso de estudantes e laje do pavimento superior ao acesso de professores. 
Observaram-se manchas de bolor nas regiões da alvenaria próxima ao solo, Figura 4b, notou-se também que já foram realizadas várias intervenções de pintura na altura de rodapés. Também é possível visualizar várias manchas de sujidade próximas às janelas, e nas bordas das lajes de cobertura do acesso de estudantes e do acesso ao Teatro, além dos frisos que fazem parte da concepção arquitetônica do estilo art déco.

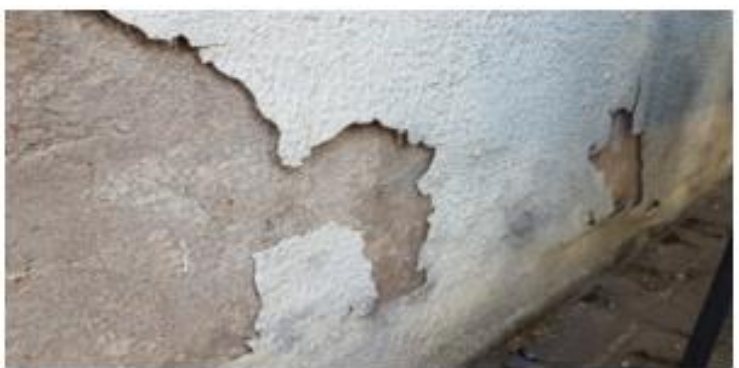

Figura 4a: Descolamento e empolamento da pintura da alvenaria

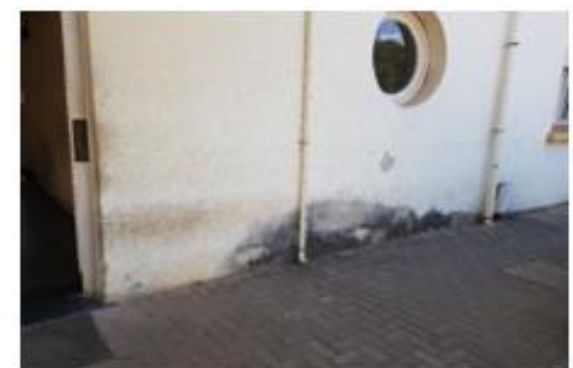

Figura 4b: Manchas de bolor próximo ao solo

O telhado é de estrutura de madeira e do tipo duas águas e, portanto, possui duas calhas ao longo de sua extensão. Alguns pontos não possuem caimento para o escoamento da água para os coletores verticais, resultando em acúmulo de água parada nas calhas, Figura 5, sendo necessário que o funcionário responsável pela limpeza faça o escorrimento da água com o auxílio de um rodo. Este procedimento é feito de duas a três vezes por semana, a depender da necessidade. Foi possível notar que as telhas são cerâmicas e algumas delas estavam danificadas, principalmente próximo às antenas de telecomunicação. Detectou-se também algumas telhas soltas e sem o encaixe correto. Além disso, a vegetação que avança por cima do telhado causa alguns transtornos com a frequente queda de folhas e flores.

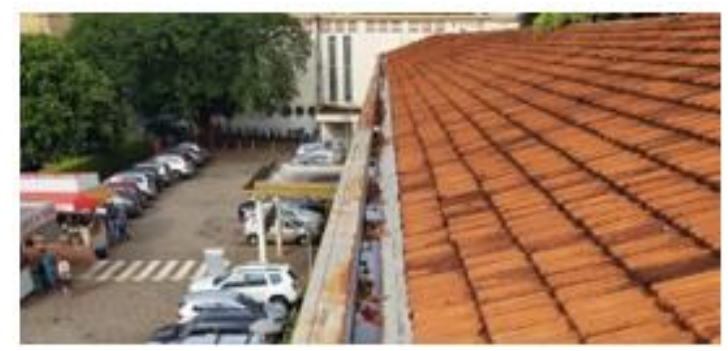

Figura 5: Acúmulo de água nas calhas do telhado duas águas

Olhando por cima das lajes de cobertura do acesso de estudantes e do acesso ao Teatro foi possível visualizar os danos causados pelo acúmulo de água. Na laje do acesso de estudantes, notou-se a existência de um dreno na lateral em uma das platibandas, Figura 6a, mas a laje não possui o caimento adequado e o tubo não coleta na totalidade a água no plano da laje. Ademais, apresenta manchas esbranquiçadas e formação de lodo (micro-organismos), mostrado na Figura 6b. Na laje do acesso ao Teatro viu-se a formação de lodo em toda sua extensão. Esta, por sua vez, possui o caimento adequado para os drenos.

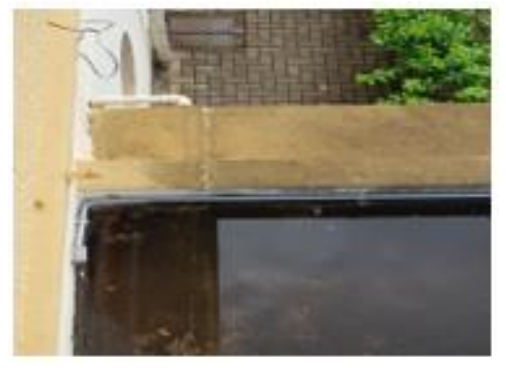

Figura 6a: Dreno lateral da cobertura de acesso de estudantes

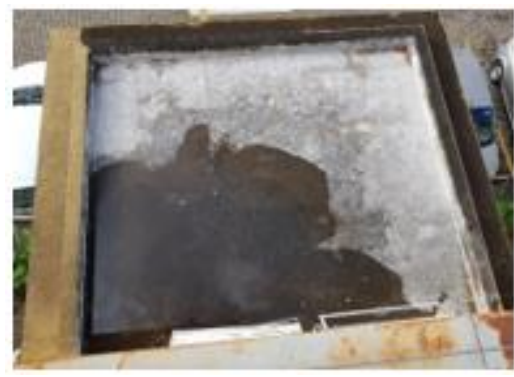

Figura 6b: Laje de cobertura do acesso de estudantes

Em relação à anamnese, para compreender os problemas reincidentes neste pavilhão, recorreu-se à GAAM (IFG - Câmpus Goiânia), responsável pelas manutenções. Em épocas chuvosas, ocorrem alguns vazamentos no telhado e molham a laje de cobertura, causando danos severos ao revestimento e pintura do teto. Esta Gerência informou que as intervenções autorizadas pelo IPHAN não são suficientes para dirimir os problemas do telhado em questão. Buscou-se o projeto da rede pluvial, mas não há registros da existência do mesmo. 
A GAAM (IFG - Câmpus Goiânia) permitiu o acesso aos ofícios, informações técnicas, diagnósticos do estado de conservação e relatórios fotográficos enviados pelo IPHAN para a Diretoria Geral do IFG - Câmpus Goiânia. Conforme o Ofício n. ${ }^{\circ}$ 105/12/Coord.Téc./Iphan-GO, foram encaminhadas as Informações Técnicas IT n. ${ }^{\circ} 018 / 12$ e IT n. ${ }^{\circ}$ 020/12 acerca de problemas de umidade e infiltrações no edifício do IFG - Câmpus Goiânia.

A IT n. ${ }^{\circ}$ 018/12 descreve a vistoria técnica para verificar as condições das paredes e muretas dos blocos tombados, especialmente quanto à presença de infiltrações na cobertura e umidade ascendente, descente e localizada, como caracterizam. Neste documento o vistoriador observou muitas paredes do primeiro pavimento com descolamento da pintura, em decorrência da umidade provinda do solo, uma vez que provavelmente não houve impermeabilização das fundações da edificação.

A IT n. ${ }^{\circ}$ 020/12 relata as causas das infiltrações e indica possíveis soluções para os problemas, estabelecendo diretrizes para as intervenções. Em alguns trechos em que a argamassa estava se desagregando, era visível em sua composição a existência de partes de saibro e a presença de grande quantidade de umidade.

O Ofício n. ${ }^{\text {o } 122 / 12 / C o o r d . T e ́ c . / I p h a n-G O ~ r e t r a t a ~ q u e ~ f o r a m ~ e n c a m i n h a d o s ~ o ~ D i a g n o ́ s t i c o ~ d o ~ E s t a d o ~ d e ~ C o n s e r v a c ̧ a ̃ o ~ e ~}$ Cronograma de Vistorias de Fiscalização. Este ofício ainda requere a apresentação das soluções dos danos referentes a infiltrações e pontos de umidade apontados no Ofício n. ${ }^{\text { }}$ 105/12 /Coord.Téc./Iphan-GO. Anexo a ele, consta o Diagnóstico do Estado de Conservação da edificação em questão, que descreve pormenorizadamente a identificação, descrição, avaliação, e situação de todos os sistemas construtivos existentes.

Como percebido, a concepção arquitetônica da fachada do bloco 100 contribui para o acúmulo de água nos telhados e coberturas. A falta de pingadeira nas janelas favorece o acúmulo de sujidade com o escoamento da água. O descolamento e empolamento da pintura na face inferior da laje do pavimento superior ao acesso de professores também insinua ser causados pela falta de pingadeira e quebra da lâmina d'água no fim da fachada, causando a umidade próxima à extremidade da laje. Para o descolamento e empolamento da pintura e manchas de bolor nas alvenarias presume-se que há umidade provindo do solo por capilaridade dos materiais empregados na alvenaria. A quantidade de telhas cerâmicas quebradas e o eventual deslocamento das mesmas com a ventania proporciona a entrada de água das chuvas para debaixo do telhado e, consequentemente, molha a laje de cobertura. Além de que o rápido acúmulo de folhagens e a falta do caimento adequado das calhas podem proporcionar o transbordamento da água das calhas para a laje de cobertura. A ausência de caimento e drenos eficientes na laje de cobertura do acesso de estudantes resulta no empoçamento da água e proliferação dos micro-organismos, formando o lodo. Na laje de cobertura do acesso ao Teatro, embora possua declividade para os drenos, há o crescimento de micro-organismos devido a umidade que o concreto absorve associado a pouca incidência de luz solar.

Como proposto pelo técnico responsável do IPHAN através das Informações Técnicas IT n ${ }^{\circ}$ 018/12 e IT n. ${ }^{\circ}$ 020/12, o problema de danos das alvenarias do pavimento térreo pode ser solucionado através da instalação de uma vala drenante, ao redor de toda a edificação e no perímetro do pátio interno, para rebaixamento do lençol freático e consequente diminuição da umidade ascendente no local. O uso de impermeabilizante pode resolver o problema por determinado tempo, mas não atuaria na causa do problema e, para resolver definitivamente esta situação, é necessário afastar a presença da umidade da base das paredes.

Em se tratando do método IBAPE/SP em 2012, tem-se o Nível 1 que é a inspeção realizada em edificações de baixa complexidade técnica e com planos de manutenção inexistentes. A análise da documentação mostrou que não existe o projeto das redes pluviais deste pavilhão, nem sequer projeto de impermeabilização e memoriais descritivos. Para a realização das intervenções, o IPHAN lista todas as restrições vigentes com a finalidade de preservar as características originais da edificação. A listagem de verificação demostra que os sistemas construtivos abrangidos foram: estrutura, impermeabilização, instalações hidráulicas, alvenaria, esquadrias, revestimentos argamassados, coberturas e telhados. Classificam-se as seguintes anomalias encontradas: manchas de bolor, descolamento e empolamento da pintura, acúmulo de sujidade e proliferação de micro-organismos como anomalias endógenas, provocadas pela umidade do solo devido falta de impermeabilização, ausência de peitoris nas janelas e falha na execução das declividades das lajes. Em relação às falhas, classificam-se como falhas de planejamento, porque são decorrentes de falhas de procedimentos e especificações inadequados, sem aderência a questões técnicas, de uso, de operação e de exposição ambiental, por parte do IPHAN. Identifica-se o grau de risco como mínimo visto que causam pequenos prejuízos à estética, sem a probabilidade de ocorrência dos riscos críticos. As prioridades podem ser definidas partindo, em ordem decrescente, com a troca das telhas e inspeção da estrutura de madeira do telhado. Depois, realizar a impermeabilização das lajes de cobertura de acesso de estudantes e ao Teatro. Quando possível, estudar a solução proposta pelo IPHAN para a execução da vala de drenagem 
com bidim no perímetro do pavilhão, para então realizar a remoção da pintura danificada, preparar o substrato e aplicar a nova pintura nas paredes.

\subsection{Comparação dos métodos empregados}

Conforme verificado no estudo de caso, o Método 1 - LICHTENSTEIN (1986) abrange mais o levantamento de subsídios para o entendimento do problema, citando o uso de exames complementares e as ações necessárias para compor a anamnese. No Método 2 - IBAPE/SP (2012), a norma explana quais documentações devem ser consultadas e também aborda uma listagem de verificação com os sistemas construtivos a serem vistoriados.

Ainda, o Método 1 - LICHTENSTEIN (1986) abrange a determinação do diagnóstico da situação patológica, interpretando as causas eficientes e coadjuvantes que contribuíram para o aparecimento dos sintomas. Por fim, estabelece que é necessário estimar o grau de incerteza e a relação custo-benefício de cada intervenção para definir a conduta mais adequada, fazendo-se a listagem das técnicas de execução e materiais e equipamentos envolvidos na realização das tarefas propostas em cada solução. Neste ponto, o Método 2 - IBAPE/SP (2012) não prescreve orientações para a definição do diagnóstico, apenas define a ordem de prioridades, recomendando que seja estabelecida em relação ao grau de risco e intensidade das anomalias e falhas. Na Tabela 1 a seguir estão apresentadas as contribuições quanto à abrangência.

Tabela 1 - Comparação dos métodos quanto à abrangência

\begin{tabular}{c|c}
\hline Método 1 - Lichenstein (1986) & Método 2 - IBAPE/SP (2012) \\
\hline $\begin{array}{c}\text { Levantamento de subsídios: exames complementares e } \\
\text { anamnese }\end{array}$ & Documentação e Listagem de verificação \\
\hline $\begin{array}{c}\text { Diagnóstico: causas eficientes e causas coadjuvantes. } \\
\text { Definição da conduta: grau de incerteza e relação custo- } \\
\text { benefício }\end{array}$ & $\begin{array}{c}\text { Não há informação para a identificação das causas } \\
\text { do problema }\end{array}$ \\
\hline $\begin{array}{c}\text { Definição de prioridades: grau de risco e } \\
\text { intensidade das anomalias }\end{array}$ \\
\hline
\end{tabular}

A aplicação dos dois métodos de inspeção predial para o mesmo estudo de caso tem a finalidade de contrastar também as particularidades de cada um dos métodos. O Método 1 - LICHTENSTEIN (1986) consiste em um procedimento para diagnóstico e recuperação de patologias das construções. Sendo assim, aprofunda-se na investigação da origem e causa do problema e na definição das ações necessárias para o tratamento.

O Método 2 - IBAPE/SP (2012) possui mais especificidades, porquanto se trata de uma norma elaborada por engenheiros, arquitetos e agrônomos para a difusão de informações para elaborar um laudo de inspeção predial atendendo às normas ABNT NBR 5674, ABNT NBR 15575-1 e, principalmente, para auxiliar na investigação da segurança e funcionalidade dos edifícios. Dessa forma, esta norma traz algumas classificações quanto ao nível de inspeção, a depender da complexidade da edificação; classificação das anomalias e falhas, sendo as anomalias as próprias não conformidades (patologias) e as falhas o que provocou a anomalia; classificação do grau de risco, considerando o perigo oferecido à saúde dos usuários, ao meio ambiente e ao patrimônio; avaliação do Plano de Manutenção ou registros das atividades realizadas e das condições de uso da edificação. Na Tabela 2Erro! Fonte de referência não encontrada. a seguir estão apresentadas as contribuições quanto à especificidade.

Tabela 2 - Comparação dos métodos quanto à especificidade

\begin{tabular}{c|c}
\hline Método 1 - Lichenstein (1986) & Método 2 - IBAPE/SP (2012) \\
\hline Investigação profunda da origem e causa do problema & $\begin{array}{c}\text { Classificação do nível de inspeção e das anomalias } \\
\text { e falhas }\end{array}$ \\
\hline Definição das ações necessárias para o tratamento & $\begin{array}{c}\text { Classificação do grau de risco e definição de } \\
\text { prioridades }\end{array}$ \\
\hline $\begin{array}{c}\text { Retroalimentação do processo para servir de subsídio a } \\
\text { futuras manifestações }\end{array}$ & $\begin{array}{c}\text { Avaliação do Plano de Manutenção e condições de } \\
\text { uso da edificação }\end{array}$ \\
\hline
\end{tabular}

\subsection{Elaboração das fichas de inspeção e cartilha de condutas}

Para a criação das fichas de inspeção, procurou-se compilar as informações mais importantes para o diagnóstico e definição da terapia que ambos os métodos forneceram. Primeiramente, deve-se identificar o local e/ou objeto, a data da vistoria e o responsável pela inspeção. Com a inspeção visual, o examinador deve preencher a descrição dos danos visualizados, a intensidade das anomalias e classificar o grau de risco através da percepção sensorial e visual. Avançando 
a inspeção para os sistemas e componentes próximos à manifestação patológica, deve-se buscar as prováveis causas e origem do problema. Por fim, após consultar a cartilha de condutas, deve-se preencher a intervenção adotada para que seja monitorado o resultado dessa decisão.

Para o diagnóstico da situação, caso não seja possível identificar a causa e origem do problema apenas com a inspeção visual, deve-se buscar informações do histórico de intervenções para a anamnese do objeto. Se ainda assim não forem suficientes para a formação do diagnóstico, são necessários exames complementares. Embora haja o risco de incorreção do diagnóstico porque as informações do edifício e intervenções anteriores são escassas, reforça-se a importância de um correto diagnóstico sobre a avaliação física da edificação, para que não sejam investidos esforços e valores aleatoriamente, além de incorrer em procedimentos de manutenção ineficientes.

Sugere-se avaliar o estado de conservação da edificação como um todo. Para isso, as fichas de inspeção podem ser usadas em vistorias de rotina e manutenção preventiva, classificando a própria ficha de inspeção, como por exemplo: componente verificado e em bom estado; componente verificado e necessitando de reparos; componente verificado e corrigido. Cada verificação deve possuir a identificação do componente no campo "local e/ou objeto" e a descrição das verificações. Caso tenha observado alguma inconformidade, preencher a classificação, intensidade e grau de risco.

Para as avaliações constantes sobre o estado do edifício, as vistorias devem verificar vários pontos dos diversos sistemas construtivos e seus elementos, conforme a listagem de verificação proposta pelo Método 2 - IBAPE/SP (2012). Os principais itens a serem observados na estrutura são infiltrações de água, fissuras e deformações, cobrimentos, existência de processos de carbonatação e corrosão das armaduras - quanto à corrosão das armaduras, verificar mais cuidadosamente a região da estrutura voltada para a fachada que retém umidade, lajes descobertas e pés de pilares; na impermeabilização são os rejuntes dos pisos cerâmicos, ralos e peças sanitárias; nas instalações hidráulicas são os ralos e sifões dos lavatórios, estanqueidade dos registros de gaveta e das válvulas de descarga e torneiras; nas instalações elétricas são o aperto das conexões e o estado dos contatos elétricos, substituindo peças que apresentarem desgaste; nas fachadas são o acúmulo de umidade nas argamassas de revestimentos externos, infiltrações nas juntas e frisos e descolamento do revestimento; nas coberturas e telhado são a estanqueidade das telhas, desobstrução e caimento das calhas e condições do madeiramento; nas alvenarias são as infiltrações, fissuras e repintura.

Para a elaboração da cartilha de condutas, considerou-se as patologias do estudo de caso, o diagnóstico e a conduta proposta para cada uma. A definição da terapia é embasada na relação custo-benefício e no grau de incerteza sobre as suas consequências e, com o auxílio das fichas de inspeção e definição do diagnóstico, espera-se que seja possível identificar qual terapia é a mais recomendada. A cartilha de condutas classifica as patologias quanto à origem, causa ou danos/efeitos e descreve os serviços necessários para o tratamento do problema. Futuramente será possível a retroalimentação da cartilha de condutas com novas patologias levantadas e estudadas e com os resultados das intervenções realizadas para servir de subsídio para o diagnóstico de ocorrências semelhantes.

\section{CONCLUSÃO}

A finalidade deste trabalho tomando como base o estudo de caso do IFG - Câmpus Goiânia foi devido aos diversos pontos visíveis que estão sendo avariados pela umidade e infiltração. A escolha da área de estudo foi bem representativa uma vez que contemplou várias patologias em comum em todo o Câmpus. A inspeção visual foi suficiente para identificar os danos causados pela umidade, mas a falta de projetos e histórico de intervenções dificulta o entendimento para a composição do diagnóstico mais provável.

Em geral, verificou-se uma grande ocorrência de patologias devido às falhas de projeto e execução, muitas vezes decorrentes também da idade das edificações. Na época em que foram construídas, na década de 1940, não haviam tais especificações para a impermeabilização dos elementos de fundação, por exemplo.

Esse estudo gerou um procedimento prático às inspeções prediais no IFG - Câmpus Goiânia com a adoção das fichas de inspeção e a cartilha de condutas que lista as prováveis causas e origens dos danos identificados tornando mais fácil definir a conduta de intervenção.

A divulgação da história da manifestação patológica e de sua solução pode ser entendida como fonte para a aquisição de subsídios necessários para o diagnóstico de ocorrências semelhantes e a definição da conduta mais satisfatória. Tendo que qualquer intervenção na edificação produz consequências em seu desempenho, o acompanhamento dos resultados e a 
comparação entre os efeitos provocados e os esperados, torna-se uma grande fonte de informações que servem para a retroalimentação da cartilha.

Com o objetivo de minimizar a ocorrência de patologias em edificações, é necessário que os construtores e projetistas façam a retroalimentação da fase de projeto com informações obtidas na fase de uso, operação e manutenção. Além das providências tomadas na fase de execução para minimizar as atividades de manutenção, deve-se estudar a implantação de um sistema de gestão da manutenção (facilities management) durante a fase de uso, operação e manutenção (DARDENGO, 2010).

\section{REFERÊNCIAS}

ANTUNES, G. R. Estudo de manifestações patológicas em revestimento de fachada em Brasília - Sistematização da incidência de casos. 2010. 178f. Dissertação de Mestrado em Estruturas e Construção Civil - Universidade de Brasília, Brasília, 2010.

ASSOCIAÇÃO BRASILEIRA DE NORMAS TÉCNICAS - ABNT. NBR 5462. Confiabilidade e manutenibilidade. Rio de Janeiro, 1994.

2012.

NBR 5674. Manutenção de edificações - Requisitos para o sistema de gestão de manutenção. Rio de Janeiro,

. NBR 15575-1. Edificações habitacionais - Desempenho - Parte 1: Requisitos gerais. Rio de Janeiro, 2013.

. NBR 14037. Diretrizes para elaboração de manuais de uso, operação e manutenção das edificações - Requisitos para elaboração e apresentação dos conteúdos. Rio de Janeiro, 2014.

CAETANO, C. IFG, no centro de Goiânia, é marco do Batismo Cultural e do estilo art déco na capital, 2018. Disponível em: <https://aproveiteacidade.com/passeios/ifg-no-centro-de-goiania-e-marco-do-batismo-cultural-e-doestilo-art-deco-na-capital/>. Acesso em: 04 mar. 2019.

CASTRO, M. D. de; MARTINS, R. M. Análise e sugestões terapêuticas das patologias de infiltração de um edifício com mais de 20 anos - Estudo de caso. 2014. 78f. Trabalho de Conclusão de Curso (Bacharelado em Engenharia Civil) - Universidade Tecnológica Federal do Paraná, Pato Branco, 2014.

CECHINEL, B. M. et al. Infiltração em Alvenaria - Estudo de caso em edifício na Grande Florianópolis. Caderno de publicações acadêmicas, Florianópolis, v. 1, n. 1, p. 18-24, 2011.

DARDENGO, C. F. R. Identificação de patologias e proposição de diretrizes de manutenção preventiva em edifícios residenciais multifamiliares da cidade de Viçosa - MG. 2010. 175f. Dissertação (Pós-graduação em Engenharia Civil) - Universidade Federal de Viçosa, Viçosa, 2010.

FLORES-COLEN, I. S. Metodologia de avaliação do desempenho em serviço de fachadas rebocadas na óptica da manutenção predictiva. 2009, 487f. Tese (Doutorado em Engenharia) Instituto Superior Técnico - Universidade de Técnica de Lisboa; Universidade Nova de Lisboa, Lisboa, 2009.

HUSSEIN, J. S. M. Levantamento de patologias causadas por infiltrações devido à falha ou ausência de impermeabilização em construções residenciais na cidade de Campo Mourão - PR. 2013. 54f. Trabalho de Conclusão de Curso (Bacharelado em Engenharia Civil) - Universidade Tecnológica Federal do Paraná, Campo Mourão, 2013.

INSTITUTO BRASILEIRO DE AVALIAÇÕES E PERÍCIAS DE ENGENHARIA - IBAPE. Norma de Inspeção Predial Nacional. São Paulo, 2012.

ISAIA, C, G. IBRACON Concreto Ensino Pesquisa e Realizações. Distribuidora Curitiba de Papéis e Livros S/A, Curitiba, ed. 1, v. 1 e 2, 2010.

LICHTENSTEIN, N. B. Patologia das construções: boletim técnico n. 6. São Paulo: EPUSP, 1986. 
MELO JÚNIOR, C. M. Metodologia para geração de mapas de danos de fachadas a partir de fotografias obtidas por veículo aéreo não tripulado e processamento digital de imagens. 2016, 376f. Tese de Doutorado em Estruturas e Construção Civil - Universidade de Brasília, Brasília, 2016.

MUNDURUCA, E. A. M. B. Reabilitação em edifícios e monumentos art déco - Métodos de avaliação dos revestimentos de fachadas. 2013. 158f. Dissertação (Mestrado em Engenharia Civil) - Universidade Federal de Goiás, Goiânia, 2013.

RODRIGUES, R. M.; JÚNIOR, A. da S. S.; LIMA, E. E. P. Erros, diagnósticos e soluções de impermeabilização na construção civil. InterScientia, João Pessoa, v. 4, n. 2, p. 19-33, 2016.

SILVA, B. C da. Investigação de manifestações patológicas em alvenarias de edifícios multipavimentos por meio de registros de assistência técnica. 2013. 199f. Dissertação (Mestrado em Engenharia Civil) - Universidade Federal de Goiás, Goiânia, 2013.

SOUZA, M. F. de. Patologias ocasionadas pela umidade nas edificações. 2008. 64f. Monografia (Especialização em Construção Civil) - Escola de Engenharia da UFMG, Belo Horizonte, 2008.

VERÇOZA, E. J. Patologia das Edificações. Porto Alegre: Editora Sagra, 1991. 172f. 